\title{
Systemic Uptake and Clearance of Chloroform by Hairless Rats Following Dermal Exposure. I. Brief Exposure to Aqueous Solutions
}

\author{
Mohammad S. Islam, ${ }^{1}$ Luhua Zhao, ${ }^{1}$ Joseph Zhou, ${ }^{1}$ Lilly Dong, ${ }^{2}$ James N. McDougal, ${ }^{2}$ and \\ Gordon L. Flynn'
}

Received May 3, 1995; revised January 12, 1996

\begin{abstract}
The systemic uptake of chloroform from dilute aqueous solutions into live hairless rats under conditions simulating dermal environmental exposure was studied. Whole blood was sampled during a 30-min immersion of an animal within water containing a known concentration of chloroform and then for $5.5 \mathrm{~h}$ following its removal from the bath. The amount of chloroform systemically absorbed was determined by comparing the AUCs of the blood concentration vs. time plots from dermal exposure to that obtained after IV infusion (for a period of $30 \mathrm{~min}$ ) of an aqueous solution containing a known amount of chioroform (positive control). Although dermal data implied two-compartment disposition characteristics, IV infusion data fit best to a three-compartment disposition. Linear pharmacokinetics was observed both by IV administration and percutaneous absorption at the dose levels studied. Chloroform was detected in the rat blood as early as $\mathbf{4}$ min following exposure. Our findings suggest that about $10.2 \mathrm{mg}$ of chloroform was systemically absorbed after dermal exposure of a rat to an aqueous solution of $0.44 \mathrm{mg} / \mathrm{ml}$. This amount is substantially higher than the predictions of mathematical risk-models put forth by some investigators. However, when expressed as the "effective" permeability coefficient $\left(K_{p}^{\text {efr }}\right)$, close agreement was noticed between our value and those estimated by others using physiologically based pharmacokinetic (PBPK) models. Also, in terms of $K_{p}^{\text {eff }}$, reasonable agreement existed between our and another investigator's past estimates of uptake based on depletion of bath level of chloroform and the actual uptake measured in our current experiments. The estimated onset of systemic entry seen here is entirely consistent with our estimate of how long it takes to establish the diffusion gradient across the stratum corneum based on tape stripping.
\end{abstract}

KEY WORDS: Chlorofo:m; blood concentration; systemic uptake; skin absorption; hairless rat.

\section{INTRODUCTION}

Recently, there has been a growing concern about the cumulative absorption of chemicals from frequent, intermittent, brief exposures to contaminated water, as might occur daily through bathing.(1) For the most part, such exposures fall short of diffusion lag times for permeation of the skin, which range from several minutes

\footnotetext{
' College of Pharmacy, The University of Michigan, Ann Arbor, Michigan 48109.

${ }^{2}$ Armstrong Laboratory, WPAFB, Ohio 45433-6573.
}

for low molecular weight compounds to several hours for heavier ones ${ }^{(2)}$ and the question has been raised if it is appropriate to use steady-state absorption algorithms to quantify such exposures. The temporal dependencies of the exposures therefore have to be resolved. Chloroform is a representative low molecular weight, lipophilic, very volatile, halogenated compound which is present as a pollutant in our water supplies, and thus a good compound to use to evaluate the unresolved issues. This chemical can be acutely toxic and is also a suspect carcinogen. ${ }^{(3)}$ Therefore, the health risk arising from frequent, brief showering/swimming of human beings in 
water containing it as a contaminant cannot be ignored, especially considering the large surface area of skin which might be exposed.

Although some literature exists on the determination of blood levels of chloroform in nonoccupationally exposed humans ${ }^{(4-7)}$ and in animals, ${ }^{(8)}$ the means of its intake has generally been other than dermal. Jorgenson and Rushbrook' ${ }^{(8)}$ 90-day subacute study in male rats and female mice, for instance, was aimed at providing toxicologic and range-finding data sufficient for setting dose levels for the chronic-phase testing of chloroform in drinking water. Aggazzotti et al. ${ }^{(9)}$ measured plasma chloroform concentrations of swimmers and visitors exposed to chloroform found in the water of three indoor swimming pools in Italy. The blood chloroform concentration depended on both the water and air concentrations, the number of swimmers, the length of swimming time, and the intensity of physical activity while in the pool. No effort was made to factor out the dermal contribution. More relevant to the present work, Bogen et $a l .{ }^{(10)}$ reported dermal uptake of chloroform after exposing hairless guinea pigs to dilute aqueous solutions (10$100 \mu \mathrm{g} / \mathrm{L}$ ) of chloroform in a closed chamber at $32^{\circ} \mathrm{C}$ for $70 \mathrm{~min}$. The authors validated their method by comparing the urinary and fecal metabolite levels obtained after dermal exposure of a rat with that after subcutaneous administration of chloroform in corn oil. Since the overall excretory data were associated with high coefficients of variation ( $\geq 88 \%, n=5$ or 6 ), the back-calculated systemic uptake values following dermal exposures would be expected to have a high degree of variability. Jo et al. ${ }^{(11.12)}$ estimated the chloroform body burden in healthy individuals taking typical showers. Differences in chloroform concentrations in exhaled breath in the course of normal showering and inhalationonly exposures were used to back out the extent of dermal absorption. No direct sampling of blood was attempted. Only a singular investigation seems to have been aimed at obtaining blood concentration-time profiles of chloroform (among other volatile organic chemicals) after its dermal absorption from an aqueous solution, that of Morgan et al. ${ }^{(13)}$. In this work, a small reservoir of the neat chemical or an aqueous solution of it was placed on the back of the animal and kept in place for $24 \mathrm{~h}$. While all of these studies offer important insights concerning chloroform's uptake, none deals totally effectively with the question of the nonstationary character of uptake associated with very brief exposures.

Earlier, ${ }^{(14)}$ we reported on the fate of chloroform taken up into hairless rat skin in the course of exposure to a well-stirred dilute aqueous solution of the chemical. The total dermal uptake was estimated by difference in the bathwater concentration of chloroform with and without a rat being present. Measured indirectly, a significant amount of chloroform appeared to reach the viable epidermis and its underlying systemic circulation with exposure times as short as $4 \mathrm{~min}$. The total amount absorbed in a 30-min exposure was estimated to be 29.4 $\mathrm{mg}$. Like studies before it, the indirect method of estimation leaves such conclusions subject to question. To clarify these issues, blood chloroform concentrations arising from short exposure of hairless rats to a dilute aqueous solution have been determined and are reported here.

\section{MATERIALS AND METHODS}

\subsection{Materials and Animals}

HPLC grade chloroform (ChromAR ${ }^{\circledR}$ HPLC) was obtained form Mallincrodt, Inc., St. Louis, MO. It contained $99 \%$ chloroform with $1 \%$ ethanol added for stabilization. Hexane used for extraction of chloroform from rat blood was purchased from Fisher Scientific. It was OPTIMA grade and met the rigid analytical requirements for use in electron capture gas chromatography and for residue and pesticide analysis. Since the animals were anesthetized during the experiments, an isothermal pad (Deltaphase ${ }^{T M}$, Braintree Scientific, Inc., Braintree, MA) was placed beneath them to provide warmth while out of the bath. The male hairless rats (CRL:CD) used in the experiments were obtained from Charles River Laboratories, Raleigh, NC. They were 15-20 weeks old, weighing between $410-535 \mathrm{~g}$.

\subsection{Bath Assembly for Hairless Rats}

A tall, 1000-ml, jacketed glass beaker formed the bath in which sedated animals were immersed. This beaker supported a restraining collar (made of stainless steel) used to keep the animal's head above the water and to provide an isolated air environment around the head from which the animal breathed. To accomplish the latter objective, the animal's head was enclosed in a glass chamber formed from an inverted beaker. The rim of this glass chamber fitted into a cylindrical groove, 66 $\mathrm{mm}$ in diameter, $4 \mathrm{~mm}$ wide and about $2 \mathrm{~mm}$ deep, notched into the collar. Air was forced into the chamber through a portal placed over the animal's head. Three symmetrically placed notches across the groove allowed excess to escape at the level of the neck. A photograph 
of the setup and dimensional details are given in our previous paper. ${ }^{(14)}$ A stainless steel rack was placed at the bottom of the beaker to support the rat and allow stirring by a magnetic stirrer placed at the bottom of the vessel. The bath water temperature was held constant at $36 \pm 0.2^{\circ} \mathrm{C}$ (nominally the skin-surface temperature of the rat) using a circulating water bath (Lauda Model M3B). The entire apparatus was placed inside a fume hood to contain all escaping chloroform.

\subsection{Preparation of the Aqueous Solution of Chloroform}

\subsubsection{Dermal Exposure Solution}

Solutions of chloroform in deionized water at $36^{\circ} \mathrm{C}$ were prepared by adding a calculated volume $(0.205$ $\mathrm{mL}$ ) of chloroform to $450 \mathrm{ml}$ of pre-warmed water in a $1000 \mathrm{ml}$ separatory funnel and then vigorously shaking the water for about $2 \mathrm{~min}$. Droplets of chloroform at the bottom of the funnel disappeared within this time. This technique ensured complete solution of the test substance and a reproducible initial concentration of 0.44 $\mathrm{mg} / \mathrm{ml}$, a concentration 3 orders of magnitude higher than the upper limit of the U.S. EPA toxicity threshold $(0.47 \mu \mathrm{g} / \mathrm{ml}){ }^{(15)}$

\subsubsection{Positive Control Solution}

For the IV experiments, $57 \mathrm{mg}(38.41 \mu \mathrm{l})$ of chloroform was dissolved in $10 \mathrm{ml}$ of deionized water at $36^{\circ} \mathrm{C}$ in a $20 \mathrm{ml}$ glass scintillation vial. This solution contained $38 \mathrm{mg}$ (assayed quantity) of chloroform in 10 $\mathrm{ml}$, corresponding to about $50 \%$ saturation. Five $\mathrm{ml}$ of this solution containing $19 \mathrm{mg}$ of chloroform were intended to be infused into the rat over a $30-\mathrm{min}$ period.

\subsection{Animal Preparation}

\subsubsection{Anesthesia}

A combination of Ketamine hydrochloride (87 $\mathrm{mg} / \mathrm{kg}$ ) and Xylazine hydrochloride $(13 \mathrm{mg} / \mathrm{kg})$, both given intramuscularly, kept each hairless rat in a sedated state for about $2.5 \mathrm{~h}$. A second injection was necessary since blood sampling was continued for up to $6 \mathrm{~h}$. The animals were anesthetized to set the canulae and kept in this state over the entire period of blood sampling.

\subsubsection{Jugular Vein Canulation}

Because frequent blood sampling took place during the experiments, canulation was done to reduce the stress to the animals. The right jugular vein only was canulated when the rat was dermally exposed to the immersion chamber because only withdrawal of blood samples was required. However, both the right and the left veins had to be canulated for the positive control experiments in order to infuse the control solution of chloroform through the left vein concurrently with blood sampling. The canulae were handprepared from Intramedic PE-50 polyethylene tubing $(0.023 " \mathrm{ID}, 0.034$ " OD; Beckton Dickinson, Sparks, MD). A small chunk of household adhesive (100\% silicone; Dow Corning Corp., Midland, MI) was applied about 1.5" from one end of each 7" piece of the tubing and let dry overnight. This bulb of glue allowed us to suture the front portion of the tubing to muscle flanking the incised area. The blunted tip of a $20 \mathrm{G}$ needle was inserted through the other end of the tubing. This served as a port of attachment and detachment of a $1 \mathrm{cc}$ luer tip syringe (used for blood withdrawal). A 1 cc tuberculin syringe was filled with heparinized saline (Heparin conc. $-20 \mathrm{units} / \mathrm{ml}$ ) and left attached to the hub of this $20 \mathrm{G}$ needle. To set the canula, the ventral skin of the rat above the shoulder was cleaned with an alcohol swab and a vertical, $2-\mathrm{cm}$ long incision was made. After locating the vein, the adjacent connective tissue was cleared away and the canula was inserted through the small cut made into the vein by a slanted needle while lifting the vein slightly. The canula was pushed inward toward the heart until blood was seen in the tubing upon pulling back the 1-cc syringe plunger. Some of the heparinized saline was then injected back toward the heart; the syringe was left in place to prevent clotting. Finally, the incision was closed with silk suture.

Exactly the same procedure was followed in canulating the left jugular vein. In order to facilitate the IV infusion of the chloroform solution from an infusion pump into a rat positioned inside the bath, a second piece of polyethylene tubing, about 11 " long, was joined to the existing piece through an union made out of the shaft of a $20 \mathrm{G}$ needle.

\subsection{Administration of the Control Solution}

The canulated animal was carefully positioned inside the bath already containing $450 \mathrm{ml}$ of deionized water at $36^{\circ} \mathrm{C}$. About $6 \mathrm{ml}$ of the chloroform infusion was withdrawn into a 5 -ml Hamilton glass syringe (GASTIGHT ${ }^{\circledR}$ Series 1000) and the luer tip of the sy- 
ringe was attached to the needle hub from the left canula. The syringe was then inserted into a Harvard Apparatus Syringe Infusion Pump 22 (Harvard Apparatus, Southnatick, MA) and $5 \mathrm{ml}$ solution was infused over $30 \mathrm{~min}$ at an infusion rate of $166.7 \mu \mathrm{l} / \mathrm{min}$. At the end of this period, the infusion line was cut, leaving only about 1 " sticking out of the sutured area. The open end of the tubing was sealed with the silicone glue.

\subsection{Blood Sampling and Extraction Procedure}

In all experiments, $100 \mu \mathrm{l}$ of venous blood were withdrawn through the right canula immediately before putting the animal inside the bath. To prevent chloroform's volatilization, this sample and others to follow were immediately transferred to a 2-ml screw capped autosampler glass vial (New Target DP from Hewlett Packard) containing $1 \mathrm{ml}$ of hexane and vortexed for 1 min on a Thermolyne Type 16700 Mixer (Barnstead/Thermolyne, Dublique, IA). The plastic cap of the vial had a disposable septum with a layer of silicone sandwiched between two linings of Teflon, the latter of which is nonadsorptive to chloroform. The same volume of blood was withdrawn with luer tipped 1-cc Hamilton glass syringes (GASTIGHT ${ }^{\circledR}$ Series 1000) at 4, 8, 20, $30,45,60,90,120,180,240,300$, and $360 \mathrm{~min}$ after putting a rat inside the bath. From 0 to $30 \mathrm{~min}$, the rat was actually in the bath. Immediately after the 30-min sample was taken, the animal was taken out of the bath, patted dry with a piece paper towel, and laid on the isothermal pad covered with adsorbent paper. The sampling was continued on the time schedule indicated. The entire procedure was performed under a fume hood which provided a laminar flow of room air at $120-130$ $\mathrm{ft} / \mathrm{min}$. The animal's head was positioned so that it was facing the fresh stream of incoming air, eliminating all chance of the animal's inhaling any chloroform.

\subsection{Gas Chromatographic Assay}

A Hewlett Packard 5890A gas chromatograph equipped with a ${ }^{63} \mathrm{Ni}$ electron-capture detector, a HP $7673 \mathrm{~A}$ autosampler, $7673 \mathrm{~A}$ controller and 3393A integrator was used for the analysis of chloroform. A capillary column $(30 \mathrm{~m} \times 0.53 \mathrm{~mm}$ ID; $1.0 \mu \mathrm{m}$ film thickness) with DB-17 as the stationary phase obtained from J \& W Scientific, Folsom, CA was used. Nitrogen was used as the carrier gas with a total flow rate of 120 $\mathrm{ml} / \mathrm{min}$ (purge vent $20 \mathrm{ml} / \mathrm{min}$, split vent $50 \mathrm{ml} / \mathrm{min}$, and column $50 \mathrm{ml} / \mathrm{min}$ ) and the column head pressure was maintained at $9 \mathrm{psig}$. The column, the injector and the detector temperatures were set at $65^{\circ} \mathrm{C}, 100^{\circ} \mathrm{C}$, and $120^{\circ} \mathrm{C}$, respectively.

Calibration curves were prepared weekly by plotting the peak areas obtained on injection of $1 \mu$ of the standard solutions against the known concentrations of chloroform in pure hexane. This calibration method was decided upon after extensive work on the assay (to be published separately). One microliter of the clear extract (top hexane layer) of each sample was directly injected into the GC column. The injection was repeated at least two times per sample. The magnetic sample insert of the autosampler was modified to make the injector syringe sample the hexane layer without touching the drop of blood at the bottom of the vial. Between injections, the $\mathrm{GC}$ injector syringe was rinsed twice with the next sample. Concentrations in the blood samples were determined by dividing the peak areas by the slope of the calibration curve. The standard curves were linear from 10 to $4000 \mathrm{pg} / \mu \mathrm{l}$ and passed through the origin. Extraction efficiency was determined by equilibrating a series of chloroform-in-hexane solutions with $100 \mu \mathrm{l}$ of rat blood in $2 \mathrm{ml} \mathrm{GC}$ autosampler vials and expressing the chloroform concentration in the hexane layer found after equilibration as the percent recovered. This proved to be near $100 \%$ at concentrations $\geq 100 \mathrm{pg} / \mu \mathrm{l}$ and ranged between $75-100 \%$ from about 10 to $100 \mathrm{pg} / \mu \mathrm{l}$.

\section{RESULTS AND DISCUSSION}

Blood profiles obtained upon infusing $19 \mathrm{mg}$ of chloroform at a steady rate into the jugular vein over 30 $\mathrm{min}$ and also after whole body exposure (up to the neck) of a separate set of rats for the same period to a $36^{\circ} \mathrm{C}$ aqueous solution of chloroform initially containing 0.44 $\mathrm{mg} / \mathrm{ml}$ of the test pollutant are provided in Fig. 1. These curves are composites of the data obtained with four animals in cases of both IV infusion and aqueous immersion. The first notable aspect of the profiles is that more than 30 min of steady infusion is obviously necessary to achieve a steady blood level. In other words, neither the IV infusion nor the percutaneous absorption curves reached a peak at the 30 -min terminus of the exposure. It is also evident from the inset of Fig. 1 that blood levels achieved as the result of dermal absorption lag only a little behind those with IV infusion. The blood levels are very sensitive to input and drop immediately upon cessation of the infusion/exposure processes. In a previous study in which tape stripping was used to measure chloroform in the surface of the skin, ${ }^{(14)}$ it was concluded that the gradient of diffusion of chloroform 


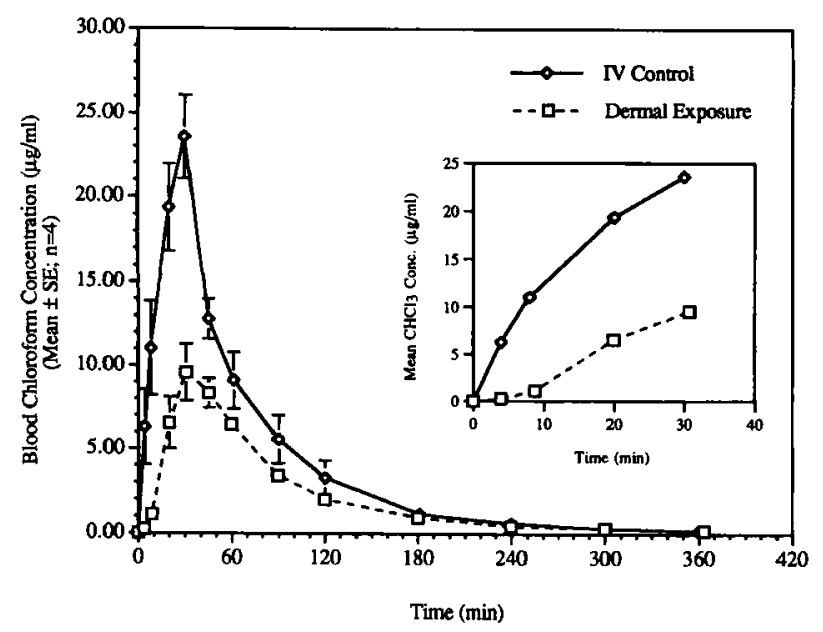

Fig. 1. Blood concentration-time profiles for chloroform after IV infusion of $19 \mathrm{mg}$ (in $5 \mathrm{ml}$ aqueous solution) over $30 \mathrm{~min}$ and after dermal exposure of the hairless rats to a $0.44 \mathrm{mg} / \mathrm{ml}$ aqueous solution for $30 \mathrm{~min}$ at $36^{\circ} \mathrm{C}$. Each data point represents average $( \pm S E)$ of four experiments.

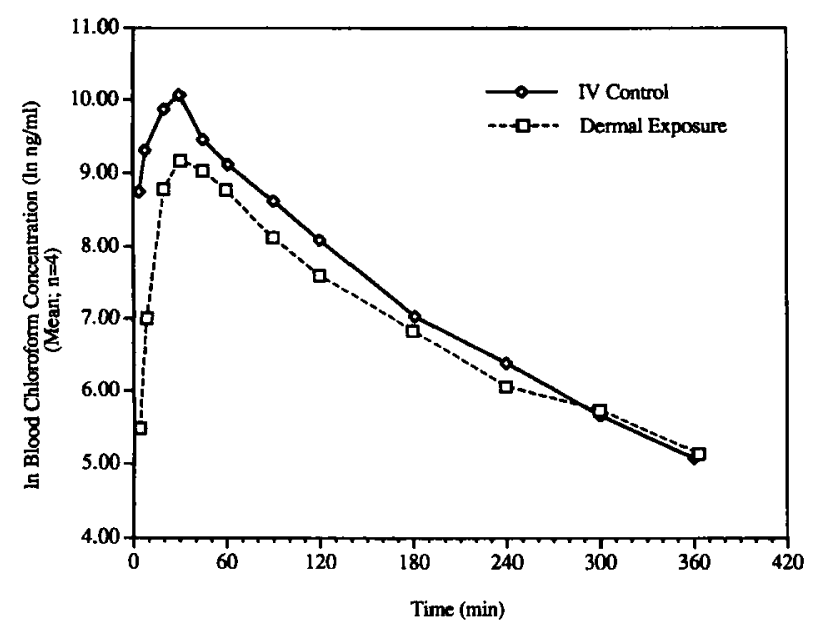

Fig. 2. Semilog plots of the same blood chloroform concentration vs. time data as used in Fig. 1 in order to delineate compartmental disposition characteristics.

across the stratum corneum is established within $8 \mathrm{~min}$ or less, the best estimate by this means being about 4 min. It is evident from the inset plot of Fig. 1 that the lag time for systemic breakthrough, that is, the time to systemic entry, is on the order of $4 \mathrm{~min}$ by pharmacokinetic analysis. This is a highly satisfying level of agreement between these remarkably different means of estimation.

In order to elucidate the compartmental characteristics of chloroform's absorption and elimination, the natural logarithms of the blood concentrations were plot- ted against time, as shown in Fig. 2. Linear pharmacokinetics was apparent at the dose levels studied in that neither of the curves shows concavity toward the time axis. At the risk of slightly overprocessing these data, the dermal exposure curve evidences one inflection point indicating a two compartmental disposition following percutaneous input. The IV infusion curve, however, actually evidences two inflection points, implying a three compartmental disposition pattern may exist. These essential features were confirmed by applying the method of residuals to both curves. ${ }^{(16)}$ The terminal elimination rate constants $\left(K, \mathrm{~min}^{-1}\right)$ shown in Table I were calculated using the last four data points from each curve. For the dermal exposure, the first-order input rate constant $\left(K_{a}, \min ^{-1}\right)$ and the first post-absorptive hybrid rate constant $\left(\alpha, \min ^{-1}\right)$, each listed in Table I, were calculated by the method of residuals. PCNONLIN Nonlinear Estimation Program (version 4.2)(17) was used to fit the experimental data to the appropriate models with the blood concentration data being weighted by a factor of $1 /$ concentration. Values for all these rate constants by both methods of estimation are found in Table I along with the estimated time $\left(T_{\max }\right)$ to reach the maximum blood concentration $\left(C_{\max }\right)$ values. The following points are notable. The peak time $\left(T_{\max }\right)$ upon infusion coincided exactly with the moment of termination of the infusion, which was $30 \mathrm{~min}$. This peak appears a few minutes (average being $4.5 \mathrm{~min}, n=4$ ) later for the data obtained via skin permeation. This slight shift, though not statistically separable, is actually expected because the skin acts as a reservoir for chloroform for a short period. Stripping data indicate this reservoir is depleted in but a few minutes. ${ }^{(14)}$ Also, regardless of which set of data is used and how the calculations are done, the terminal elimination rate constants are all in good agreement, lying between 0.005 and $0.011 \mathrm{~min}^{-1}$.

The areas under the curves (AUCs) were calculated for the blood concentration-time profiles using the trapezoidal rule. ${ }^{(16)}$ To obtain $\mathrm{AUC}_{0-\infty}$, the area from the last concentration datum point, $C_{n}$, to infinity was set equal to $C_{n} / K$ and this was added to the area, $\mathrm{AUC}_{0-\mathrm{C}_{n}}$. These parameters too are listed in Table $\mathrm{I}$. The best-fit estimates in the table are for a two-compartment model (first-order absorption with lag time) in the instance of the dermal data but for a three-compartment model for the IV infusion data with known zero-order input.

A few investigators have reported pharmacokinetics of chloroform after oral and IV administration in humans $^{(18,19)}$ and in rodents. ${ }^{(20-22)}$ Fry et al. ${ }^{(19)}$ monitored chloroform concentration in the blood, urine, and in expired air as well as the concentration of its metabolite, $\mathrm{CO}_{2}$, in the expired air of human subjects after oral ad- 
Table I. Pharmacokinetic Parameters for the Absorption and Disposition of Chloroform Obtained by Applying Graphical Methods ${ }^{a}$ to the Experimental Data and the Best Estimates by Fitting the Data ${ }^{h}$ to Compartmental Models Using PCNONLIN

\begin{tabular}{|c|c|c|c|c|c|c|c|}
\hline & $\alpha\left(\min ^{-1}\right)$ & $\beta\left(\min ^{-1}\right)$ & $K\left(\min ^{-1}\right)$ & $\begin{array}{c}C_{\max } \\
(\mu \mathrm{g} / \mathrm{ml})\end{array}$ & $\begin{array}{c}T_{\max } \\
(\min )\end{array}$ & $\begin{array}{c}\mathrm{AUC}_{0-\pi} \\
\left(\mu \mathrm{g} \cdot \mathrm{min}^{\left.-\mathrm{ml}^{-1}\right)}\right.\end{array}$ & \\
\hline \multicolumn{8}{|c|}{ IV infusion (3-compartment disposition) } \\
\hline $\begin{array}{l}\text { Graphical } \\
\text { methods }\end{array}$ & $\begin{array}{c}0.093 \\
( \pm 0.014)\end{array}$ & $\begin{array}{c}0.034 \\
( \pm 0.007)\end{array}$ & $\begin{array}{c}0.011 \\
( \pm 0.002)\end{array}$ & $\begin{array}{c}235.68 \\
( \pm 26.57)\end{array}$ & $\begin{array}{c}30 \\
( \pm 0)\end{array}$ & $\begin{array}{c}14843.37 \\
( \pm 1535.43)\end{array}$ & \\
\hline \multirow[t]{2}{*}{ Best-fit estimate } & 0.160 & 0.019 & 0.005 & 238.10 & 30 & 14507.26 & \\
\hline & $K_{u}\left(\min ^{-1}\right)$ & $\alpha\left(\min ^{-1}\right)$ & $K\left(\min ^{-1}\right)$ & $\begin{array}{l}\text { Lag time } \\
\text { (min) }\end{array}$ & $\begin{array}{c}C_{\max } \\
(\mu \mathrm{g} / \mathrm{ml})\end{array}$ & $\begin{array}{c}T_{\max } \\
(\min )\end{array}$ & $\begin{array}{c}\mathrm{AUC}_{0-x} \\
\left(\mu \mathrm{g} \cdot \min \cdot \mathrm{ml}^{-1}\right)\end{array}$ \\
\hline \multicolumn{8}{|c|}{ Dermal (2-compartment disposition) } \\
\hline $\begin{array}{l}\text { Graphical } \\
\text { methods }\end{array}$ & $\begin{array}{c}0.069 \\
( \pm 0.019)\end{array}$ & $\begin{array}{c}0.033 \\
( \pm 0.078)\end{array}$ & $\begin{array}{c}0.007 \\
( \pm 0.002)\end{array}$ & $\begin{array}{c}4 \\
( \pm 0)\end{array}$ & $\begin{array}{c}99.17 \\
( \pm 13.83)\end{array}$ & $\begin{array}{c}34.5 \\
( \pm 3.57)\end{array}$ & $\begin{array}{c}7973.91 \\
( \pm 896.75)\end{array}$ \\
\hline Best-fit estimate & 0.056 & 0.030 & 0.007 & 7.60 & 87.49 & 32.83 & 7813.14 \\
\hline
\end{tabular}

ministration of a capsule containing $500 \mathrm{mg}$ of chloroform in $1 \mathrm{ml}$ olive oil. The blood level data declined in a biphasic fashion similar to what we have found in our dermal exposure experiments. Their reported average ( $n$ $=4$ ) half-life for the first post-absorptive disposition corresponds to a rate constant of $0.049 \mathrm{~min}^{-1}$ which closely matches the value of $\alpha=0.033 \mathrm{~min}^{-1}$ in hairless rats $(n=4)$ found herein. The average value of the terminal disposition half-life (90 $\mathrm{min}, n=4)$, reported in the Fry et al.'s study, corresponded to a rate constant of $0.008 \mathrm{~min}^{-1}$, which also closely matched our observed $\mathrm{K}$ of $0.007 \mathrm{~min}^{-1}$ (Table I) in hairless rats $(n=$ 4). Chiou ${ }^{(18)}$ used the data generated by Fry et al. to develop equations for predicting the extent of pulmonary and hepatic metabolism of chloroform. Both sources concluded that about $50 \%$ of the orally administered chloroform is excreted unchanged in the expired air and the rest metabolized in the liver and excreted as $\mathrm{CO}_{2}$ through the lungs. Since our dermal exposure experiments with hairless rats resulted in comparable values of the disposition rate constants, it is reasonable to assume that chloroform, absorbed dermally from an aqueous solution of about $0.4 \mathrm{mg} / \mathrm{ml}$, will be metabolized and cleared from the rat body to similar extents as observed with humans after oral administration of $500 \mathrm{mg}$. Withey et al. ${ }^{(20)}$ monitored blood levels of chloroform after intragastric administration of the chemical dissolved in $5 \mathrm{ml}$ of water and equal volume of corn oil. After giving an aqueous solution dose of $75 \mathrm{mg} / \mathrm{kg}$ to male Wistar rats (body weight $-400 \mathrm{~g}$ ), the authors observed saturable elimination kinetics from the log blood concentration-time curves. Although we infused about $42 \mathrm{mg} / \mathrm{kg}$ [control experiment, rat's average body wt. = $428 \mathrm{~g}( \pm \mathrm{SE}=9.3 ; n=4)]$ and submerged the hairless rats [average body wt. $=481 \mathrm{~g}( \pm \mathrm{SE}=19.2 ; n=4)$ ] in $450 \mathrm{ml}$ water having an initial amount of $200 \mathrm{mg}$ chloroform (dermal exposure experiment), the log blood concentration-time curve clearly demonstrated linear (unsaturable) elimination kinetics (Fig. 2). Withey and Collins $^{(21)}$ reported pharmacokinetics of chloroform in male Wister rats $(400 \mathrm{~g})$ after IV bolus administration of $1-\mathrm{ml}$ aqueous solution at five different dose levels (3$15 \mathrm{mg} / \mathrm{kg}$ ). Chloroform reportedly conferred three-compartment disposition characteristics within the rat model at all dose levels. These authors found significantly decreasing values for the disposition rate constants $(\alpha, \beta$, and $\gamma$ ) with an increase in dose. This would imply dosedependent disposition kinetics. Michaelis-Menten type metabolism kinetics of chloroform was also observed after inhalation exposure of male Osborne-Mendel rats and male $\mathrm{B} 6 \mathrm{C} 3 \mathrm{~F} 1$ mice to the radiolabeled chemical.(22) At the highest dose $(15 \mathrm{mg} / \mathrm{kg})$ studied by Withey and Collins, ${ }^{(21)}$ the model-estimated values for $\alpha, \beta$, and $\gamma$ were $0.35 \mathrm{~min}^{-1}, 0.07 \mathrm{~min}^{-1}$, and $0.013 \mathrm{~min}^{-1}$, respectively. These values are systematically higher than the corresponding best-fit values $\left(0.16 \mathrm{~min}^{-1}, 0.019 \mathrm{~min}^{-1}\right.$, and $0.005 \mathrm{~min}^{-1}$ ) we have obtained following IV infusion (Table I, $K$ represents $\gamma$ ). This is not surprising since, at our IV infusion dose of about $42 \mathrm{mg} / \mathrm{kg}$, one expects about a 2.5 -fold decrease in these pharmacokinetic parameters as compared to a $15 \mathrm{mg} / \mathrm{kg}$ dose, this expectation being drawn in light of the nonlinear 
Table II. Comparison of the Amount (mg) of Chloroform Dermally Taken Up by the Hairless Rat (over $\left.464.4 \mathrm{~cm}^{2}\right)^{\circ}$ as Estimated by Using Different Equations ${ }^{(23-25)}$ with Our Found Values

\begin{tabular}{|c|c|c|c|c|c|c|}
\hline $\begin{array}{l}\text { Exposure time } \\
\qquad(\mathrm{min})\end{array}$ & $\begin{array}{c}\text { EPA } \\
(1992)^{(23)}\end{array}$ & $\begin{array}{l}\text { McKone and } \\
\text { Howd }\end{array}$ & $\begin{array}{l}\text { Cleek and } \\
\text { Bunge }^{(25)}\end{array}$ & $\begin{array}{c}\text { Islam et al. }{ }^{(14)} \\
\text { (total uptake found) }\end{array}$ & $\begin{array}{c}\text { This paper } \\
\text { (systemic uptake } \\
\text { found) })^{b}\end{array}$ & $\begin{array}{c}\text { Islam et al. } .^{(14)} \\
\text { (only skin uptake) }^{(\mathrm{c})}\end{array}$ \\
\hline 4 & 1.26 & 2.06 & 0.71 & 9.6 & & 1.0 \\
\hline 8 & 1.78 & 2.24 & 1.00 & 12.0 & & 1.5 \\
\hline 15 & 2.44 & 3.01 & 1.37 & 19.2 & & 1.4 \\
\hline 30 & 3.45 & 4.65 & 1.93 & 29.4 & 10.21 & 1.4 \\
\hline
\end{tabular}

metabolism observed by Withey and Collins ${ }^{(21)}$ and Corley et al. ${ }^{(22)}$

Since our prime objective in this study was to assess the chloroform body burden arising from its systemic uptake during an exposure to a dilute aqueous solution, we utilized the AUC after IV infusion as the reference standard to quantify the amount of chloroform absorbed over the $30 \mathrm{~min}$ of exposure. We decided to put this calculated systemic uptake value in Table II alongside our previously reported total uptake found by difference by direct sampling of the bath water ${ }^{(14)}$ as well as the values predicted by risk assessment models suggested by other investigators. ${ }^{(23-25)}$ Although we determined the systemic uptake only after 30-min exposure in this study by simply using the ratio of AUCs after IV infusion and dermal exposure, the same technique would provide proportional values for shorter dermal exposure times. It is clear that the systemic uptake of chloroform found by following the depletion of chloroform from the bath water over a period of $30 \mathrm{~min}$ is about 3 times higher than that determined by blood sampling even after subtracting stratum corneum bound chloroform from the former assessment. Local tissue distribution and concentration of the compound within the viable epidermis, dermis, and hypodermis likely play roles in this quantitative discrepancy. Despite this factor, given the general ease of following bath levels and the general difficulty of quantifying blood levels, we are encouraged that the level of agreement between the two methods may qualify the simpler procedure as a reasonable means for assessing uptake and attending risk, especially since it will inevitably err on the high side, possibly by several multiples, and thus provide a properly conservative risk statement. With the concentrations of chloroform used in our study, a Michaelis-Menten type metabolism kinetics was not apparent from the blood concentration- time curves. Thus the rates and extents of metabolism of chloroform following the IV administration and dermal exposure scenarios can be presumed to be directly proportional to the corresponding doses. Therefore they do not appear to be a factor of consequence relative to the discrepancy in uptake measured by the two methods (bath-water sampling vs. direct blood sampling of chloroform). Consequently, we tentatively conclude that the amount absorbed based on the blood level AUCs of intact chloroform underestimate, at least to some extent, the actual amounts of chloroform reaching the internal tissues of the rat.

Recently, in an attempt to build a comprehensive model, Bogen ${ }^{(26)}$ reviewed and reanalyzed the experimental data on percutaneous absorption of nine different organic chemicals, including chloroform. He couched the data of several investigators in terms of an effective or time-weighted-average permeability constant, $K_{p}^{\text {eff }}$. $K_{p}^{\text {eff }}$, as defined by McKone, ${ }^{(27)}$ is a measure of the effective permeability taking into account the concerted processes of partitioning and diffusion prior to and during steady state absorption. $K_{p}^{\text {eff }}$ has the property that it represents the volume of the exposure-chamber water cleared of the compound of interest per unit area of exposed surface per unit time. This gives it units of $\mathrm{ml} / \mathrm{cm}^{2} / \mathrm{hr}$ or effectively $\mathrm{cm} / \mathrm{hr}$, the latter, of course, being the ordinary units of the mass transfer coefficient or permeability coefficient expressed within Fick's Laws. Of particular importance to this paper, Bogen ${ }^{(26)}$ attempted to harmonize the PBPK (physiologically-based pharmacokinetic) parameters reported by Chinery and Gleason $^{(28)}$ and McKone(27) and his own effective permeability value (calculated), ${ }^{(10)}$ all using the experimental data of Jo et al. ${ }^{(11,12)}$ Included in this analysis was the effective permeability value of chloroform obtained by the disappearance method applied to guinea pigs im- 
Table III. Comparison of the $K_{p}^{\text {eff }}$ Values Experimentally Determined or Estimated Using Various Models by Different Investigators Using Different Species

\begin{tabular}{|c|c|c|c|c|c|c|}
\hline Reference & Species & $\begin{array}{l}\text { Exposed } \\
\text { surface area } \\
\quad\left(\mathrm{cm}^{2}\right)\end{array}$ & $\begin{array}{l}\text { Duration of } \\
\text { exposure } \\
\text { (min) }\end{array}$ & $\begin{array}{l}\text { Concentration } \\
\text { of } \mathrm{CHCl}_{3} \text { in } \\
\text { water }(\mathrm{mg} / \mathrm{ml})\end{array}$ & $\begin{array}{c}\text { Fraction of } \mathrm{CHCl}_{3} \\
\text { volatilized before } \\
\text { dermal contact }\end{array}$ & $\begin{array}{c}K_{p}^{\mathrm{eff}} \\
(\mathrm{cm} / \mathrm{hr})\end{array}$ \\
\hline This paper & Hairless rat & 513.3 & 30 & 0.44 & None & 0.09 \\
\hline Islam et al..$^{(14)}$ & Hairless rat & 464.4 & 30 & 0.44 & None & 0.29 \\
\hline model using Islam et al.'s data) $)^{(14)}$ & Hairless rat & 464.4 & 30 & 0.44 & None & 0.034 \\
\hline $\begin{array}{l}\text { McKone and Howd }{ }^{(24)} \text { (based on a } \\
\text { mathematical model using Islam et } \\
\text { al.'s data) })^{(4)}\end{array}$ & Hairless rat & 464.4 & 30 & 0.44 & None & 0.045 \\
\hline $\begin{array}{l}\text { Cleek and Bunge }{ }^{(2 s)} \text { (based on a } \\
\text { mathematical model using Islam et } \\
\text { al.'s data) })^{(14)}\end{array}$ & Hairless rat & 464.4 & 30 & 0.44 & None & 0.019 \\
\hline Bogen et al. ${ }^{(10)}$ & $\begin{array}{l}\text { Hairless } \\
\text { guinea pig }\end{array}$ & $280-316$ & 70 & $(0.2-1.1) \times 10^{-4}$ & None & $\begin{array}{c}0.13 \\
( \pm \mathrm{SD}=0.04, n=6)\end{array}$ \\
\hline $\begin{array}{l}\text { Bogen et al. }{ }^{(10)} \text { (based on Jo et al.'s } \\
\text { data) })^{(11.12)}\end{array}$ & Human & 14,400 & 0.17 & $(5.3-35.9) \times 10^{-6}$ & 0.66 & 0.16 \\
\hline $\begin{array}{l}\text { Bogen }^{(26)} \text { ("adjusted reference" es- } \\
\text { timate based on preceding data) }\end{array}$ & Human & 18,000 & 0.17 & $(5.3-35.9) \times 10^{6}$ & 0.55 & 0.13 \\
\hline $\begin{array}{l}\text { Chinery and Gleason }{ }^{(28)} \text { (based on Jo } \\
\text { et al.'s data) })^{(11.12)}\end{array}$ & Human & 18,000 & 0.17 & $(5.3-35.9) \times 10^{-6}$ & 0.61 & $\begin{array}{l}0.20 \text { (range: } \\
0.16-0.36 \text { ) }\end{array}$ \\
\hline $\begin{array}{c}\text { Bogen }^{(26)} \text { (" "adjusted reference" es- } \\
\text { timate based on preceding data) }\end{array}$ & Human & 18,000 & 0.17 & $(5.3-35.9) \times 10^{-6}$ & 0.55 & $\begin{array}{l}0.11 \text { (range: } \\
0.086-0.19 \text { ) }\end{array}$ \\
\hline $\begin{array}{l}\text { McKone }{ }^{(27)} \text { (based on Jo et al.'s } \\
\text { data) }\end{array}$ & Human & 20,000 & 0.17 & $(5.3-35.9) \times 10^{-6}$ & 0.55 & $\begin{array}{l}0.20 \text { (range: } \\
0.16-0.42 \text { ) }\end{array}$ \\
\hline $\begin{array}{c}\text { Bogen }^{(26)} \text { ("adjusted reference" es- } \\
\text { timate based on preceding data) }\end{array}$ & Human & 18,000 & 0.17 & $(5.3-35.9) \times 10^{-6}$ & 0.55 & $\begin{array}{l}0.14 \text { (range: } \\
0.11-0.29 \text { ) }\end{array}$ \\
\hline
\end{tabular}

mersed in water for $70 \mathrm{~min} .{ }^{(10)}$ In that review, ${ }^{(26)}$ Bogen also reported $K_{p}^{\text {eff }}$ values (so-called adjusted reference estimates) smaller than the originals for all the above testing after adjusting Jo et al.' $\mathrm{s}^{(11,12)}$ data for presumed evaporative losses of chloroform and also for contact with a body surface measuring $18,000 \mathrm{~cm}^{2} . K_{p}^{\text {eff }}$ values can also be calculated from dermal uptake data we've reported previously, ${ }^{(14)}$ the amounts predicted from literature models applied to those data and the systemic uptake amount found in our present study (as shown in Table II) simply by dividing those amounts by the exposed surface areas of the hairless rats calculated based on the average body weights using a mathematical model (Table II), the concentration of chloroform in the water (initially $0.44 \mathrm{mg} / \mathrm{ml}$ ) and exposure time $(30 \mathrm{~min}$ ). The values we've arrived at this way are placed alongside those of Bogen ${ }^{(26)}$ in Table III. It is readily seen that $K_{p}^{\text {eff }}$ values drawn from our own experimental uptake values $(0.09$ and $0.29 \mathrm{~cm} / \mathrm{hr})$ agree well with those from the literature. However, $K_{p}^{\text {eff }}$ values calculated from uptake values based on the three physical models ${ }^{(23-25)}$ (last column, rows 4-6 of Table III) are only one-third to onefifth of those from the literature.

It is clear from the information found in Tables II and III that, no matter how expressed, the systemic uptake of chloroform determined in our present study measurably exceeds the predictions of the physical models put forth by EPA, ${ }^{(23)}$ McKone and Howd, ${ }^{(24)}$ and Cleek and Bunge. ${ }^{(25)}$ At one-half the systematically measured value (by us), the model of McKone and Howd $\mathrm{d}^{(24)}$ is closest to the experimental mark (Table II). Moreover, our data on bath depletion suggest that the total uptake of chloroform by the rat is over twice that which is measured systematically. This of course has an additional effect of magnifying the discrepancies between experimental values and physical model estimates, possibly doubling or trebling them. The PBPK models found in the literature ${ }^{(27.28)}$ seem to do a better predictive job. However, a closer look at Table III tells us that the adjusted reference estimates of $K_{p}^{\text {eff }}$, as calculated by Bogen, ${ }^{(26)}$ are somewhat smaller than the corresponding original estimates and fall midway between the $K_{p}^{\text {eif }}$ val- 
ues form our present systemic uptake study and that from our earlier study involving the uptake of chloroform into the rat as measured by the depletion of the chemical from the bath the animal was immersed in. ${ }^{(14)}$

Two important points emerge from the above discussion. First, regardless of how the body burden is calculated in our two experimental works, the actual uptake of chloroform and therefore risks associated with dermal exposure to it are higher than the predictions made by three mathematical models. ${ }^{(23-25)}$ Bogen et al. reached the same conclusion ${ }^{(10)}$ when comparing the in vivo uptake of nine organic chemicals, including chloroform, against the predictions of the models. Second, in our hands at least, the bath depletion method ${ }^{(14)}$ seems to have good predictive value. Using hairless rats, we have reported a $K_{p}^{\text {eff }}$ of $0.29 \mathrm{~cm} / \mathrm{hr}$ which, although about twice the experimental value of $0.13 \mathrm{~cm} / \mathrm{hr}$ obtained by Bogen et $a l .{ }^{(10)}$ using hairless guinea pigs, falls midway in the range of $K_{p}^{\text {eff }}$ values (last column, rows 10 and 12, Table III) drawn from the two PBPK models. ${ }^{(27,28)}$

\section{REFERENCES}

1. A. L. Bunge, G. L. Flynn, and R. H. Guy, "Predictive Model for Dermal Exposure Assessment," in R. G. M. Wang (ed.), Water Contamination and Health (Marcel Dekker, New York, 1994).

2. G. L. Flynn, "Physicochemical Determinants of Skin Absorption," in T. R. Gerrity and C. J. Henry (eds.), Principles of Routeto-Route Extrapolation for Risk Assessment (Elsevier Science Publishing Company, New York, 1990) pp. 93-128.

3. S. Budavari (ed.), The Merck Index (11th Ed.) (Merck and Co., Rahway, NJ, 1989).

4. H. Hajimiragha, U. Ewers, R. Jansen-Rosseck, and A. Brockhaus, "Human Exposure to Volatile Halogenated Hydrocarbons from the General Environment," Int. Archives Occup. Environ. Health 58, 141-150 (1986).

5. R. Kroneld, "Chloroform in Tap Water and Human Blood," Bulletin Environ. Contam. Toxicol. 36, 477-483 (1986).

6. C. D. Pfaffenberger and A. J. Peoples, "Long-term Variation Study of Blood Plasma Levels of Chloroform and Related Purgeable Compounds," Journal of Chromatography 239, 217-226 (1982).

7. D. L. Ashley, M. A. Bonin, F. L. Cardinali, J. M. McCraw, and J. V. Wooten, "Blood Concentrations of Volatile Organic Compounds in a Nonoccupationally Exposed US Population and in Groups with Suspected Exposure,' Clin. Chem. 40(7), 1401-1404 (1994).

8. T. A. Jorgenson and C. J. Rushbrook, Effects of Chloroform in the Drinking Water of Rats and Mice: Ninety-day Subacute Toxicity Study, U.S. Environmental Protection Agency, Report No. EPA-600/1-80-030, July (1980).

9. G. Aggazzotti, G. Fantuzzi, P. L. Tartoni, and G. Predieri, "Plasma Chloroform Concentrations in Swimmers Using Indoor Swimming Pools," Arch. Environ. Health 45(3), 175-179 (1990).

10. K. T. Bogen, B. W. Colston, and L. K. Machicao, "Dermal Absorption of Dilute Aqueous Chloroform, Trichloroethylene, and
Tetrachloroethylene in Hairless Guinea Pigs," Fundamentals of Applied Toxicology 18, 30-39 (1992).

11. W. K. Jo, C. P. Weisel, and P. J. Lioy, "Routes of Chloroform Exposure and Body Burden from Showering with Chlorinated Tap Water," Risk Analysis 10(4), 575-580 (1990).

12. W. K. Jo, C. P. Weisel, and P. J. Lioy, "Chloroform Exposure and the Health Risk Associated with Multiple Uses of Chlorinated Tap Water," Risk Analysis 10(4), 581-585 (1990).

13. D. L. Morgan, S. W. Cooper, D. L. Carlock, J. J. Sykora, B. Sutton, D. R. Mattie, and J. N. McDougal, "Dermal Absorption of Neat and Aqueous Volatile Organic Chemicals in the Fischer 344 Rat," Environ. Research 55, 51-63 (1991).

14. M. S. Islam, L. Zhao, J. N. McDougal, and G. L. Flynn, "Uptake of Chloroform by Skin During Short Exposures to Contaminated Water," Risk Analysis 15, 343-352 (1995).

15. U.S. Environmental Protection Agency (EPA), National Organic Monitoring Survey, Tech. Supp. Div. Off. of Water Supply, Cincinnati, Ohio (1977).

16. M. Gibaldi and D. Perrier, Pharmacokinetics (2nd Ed.) (Marcel Dekker, New York, 1982).

17. PCNONLIN, version 4.2, Scientific Consulting Inc., Apex, NC, USA.

18. W. L. Chiou, "Quantitation of Hepatic and Pulmonary First-Pass Effect and Its Implications in Pharmacokinetic Study. I. Pharmacokinetics of Chloroform in Man," Journal of Pharmacokinetics and Biopharmaceutics 3(3), 193-201 (1975).

19. B. J. Fry, T. Taylor, and D. E. Hathway, "Pulmonary Elimination of Chloroform and Its Metabolite in Man," Archives of Int. Pharmacodyn. Therapy 196, 98-111 (1972).

20. J. R. Withey, B. T. Collins, and P. G. Collins, "Effect of Vehicle on the Pharmacokinetics and Uptake of Four Halogenated Hydrocarbons from the Gastrointestinal Tract of the Rat," Journal of Applied Toxicology 3(5), 249-253 (1983).

21. J. R. Withey and B. T. Collins, "Chlorinated Aliphatic Hydrocarbons Used in the Foods Industry: The Comparative Pharmacokinetics of Methylene Chloride, 1,2 Dichloroethane, Chloroform and Trichloroethylene after I.V. Administration in the Rat," $J$. Environ. Pathol. Toxicology 3, 313-332 (1980).

22. R. A. Corley, A. L. Mendrala, F. A. Smith, D. A. Staats, M. L. Gargas, R. B. Conolly, M. E. Andersen, and R. H. Reitz, "Development of a Physiologically Based Pharmacokinetic Model for Chloroform," Toxicol. Applied Pharmacology 103, 512-527 (1990).

23. U.S. Environmental Protection Agency (EPA), Dermal Exposure Assessment: Principles and Applications, Report No. EPA/600/891/011B, Office of Health and Environmental Assessment, U.S. EPA, Washington, D.C. 20460 (1992).

24. T. E. McKone and R. A. Howd, "Estimating Dermal Uptake of Nonionic Organic Chemicals from Water and Soil. Part 1. Unified Fugacity-based Models for Risk Assessments," Risk Analysis 12, 543-557 (1992).

25. R. L. Cleek and A. L. Bunge, "A New Method for Estimating Dermal Absorption from Chemical Exposure. 1. General Approach," Pharmaceutical Research 10(4), 497-506 (1993).

26. K. T. Bogen, "Models Based on Steady-State in Vitro Dermal Permeability Data Underestimate Short-Term in Vivo Exposures to Organic Chemicals in Water," Journal of Expos. Anal. Environ. Epidem. 4(4), 457-475 (1994).

27. T. E. McKone, "Linking a PBPK Model for Chloroform with Measured Breath Concentrations in Showers: Implications for Dermal Exposure Models," Journal of Expos. Anal. Environ. Epidemiology 3(3), 339-365 (1993).

28. R. L. Chinery and A. K. Gleason, "A Compartmental Model for the Prediction of Breath Concentration and Absorbed Dose of Chloroform After Exposure While Showering," Risk Analysis 13(1), 51-62 (1993). 